\title{
Hydroprocessing of Fischer-Tropsch biowaxes to second-generation biofuels
}

\author{
Harald Walter Schablitzky • J. Lichtscheidl • \\ K. Hutter • Ch. Hafner $\cdot$ R. Rauch $\cdot$ H. Hofbauer
}

Received: 20 October 2010 /Revised: 10 December 2010 /Accepted: 20 December 2010 /Published online: 25 January 2011

(C) Springer-Verlag 2011

\begin{abstract}
Upgrading of Fischer-Tropsch (FT) biowaxes to second-generation biofuels via hydroprocessing is the final step for increasing the fuel amount of the overall biomass conversion route: gasification of lignocellulosic biomass, FT synthesis, and hydroprocessing. The typical FT product portfolio consists of high molecular weight paraffinic waxes as the main product and FT fuels in the diesel and naphtha boiling range. OMV's objective and contribution to the project focus on achieving coprocessing of FT biowaxes with fossil feedstock using existing hydrotreating plants of crude oil refineries. Various test runs have been examined with a conventional refining catalyst under mild conditions $\left(380-390^{\circ} \mathrm{C}, 5.8 \mathrm{MPa}\right.$; WHSV, $\left.0.7-1.3 \mathrm{~h}^{-1}\right)$ in a pilot plant. Pure FT biowax is converted to gases, fuels, and an oil/ waxy residue in a fixed-bed reactor with a porous catalyst
\end{abstract}

H. W. Schablitzky $(\bowtie) \cdot$ C. Hafner

Centre of Excellence-Fuels, Innovation and Quality,

OMV Refining \& Marketing,

Mannswörther Straße 28,

2320 Schwechat, Austria

e-mail: harald.schablitzky@omv.com

J. Lichtscheidl $\cdot$ K. Hutter

New Technology, OMV Refining \& Marketing,

Mannswörther Straße 28,

2320 Schwechat, Austria

R. Rauch $\cdot$ H. Hofbauer

Bioenergy 2020+,

Inffeldgasse $21 \mathrm{~b}$,

8010 Graz, Austria

H. Hofbauer

Institute of Chemical Engineering,

Vienna University of Technology,

Getreidemarkt 9/166,

1060 Vienna, Austria layer technology. The presence of hydrogen in the reaction chamber reduces the fast deactivation of the catalyst caused by the formation of a coke layer around the catalyst particle surface and saturates cracked hydrocarbon fragments. Another approach is the creation of synthetic biodiesel components with excellent fuel properties for premium fuel application. Basically, premium diesel fuel differs from standard diesel quality by cetane number and cold flow properties. Hydroprocessed synthetic biodiesel (HPFT diesel) has compared to conventional diesel advantages in many aspects. Depending on the catalyst selected, premium diesel quality can be obtained by shifting cold flow operability properties of HPFT fuels to a range capable even under extreme cold conditions. In addition, a highquality kerosene fraction is obtained to create bio jet fuels with an extremely deep freezing point, as low as $-80^{\circ} \mathrm{C}$. The isomerization degree, as well as the carbon number distribution of high paraffinic profile, and the branching degree have a major impact on the cold flow properties and cetane number. FT diesel has, compared to HPFT diesel, a slightly higher derived cetane number $(\mathrm{DCN}>83)$ and a cloud point of $-9^{\circ} \mathrm{C}$, whereas HPFT diesel reaches values as low as $-60^{\circ} \mathrm{C}$. Although the HPFT naphtha obtained consists of high amounts of isoparaffins, the RON/ MON values are comparable to fossil straight-run naphtha. The reason is that the branching degree of isoparaffins from the naphtha fraction is not sufficiently high enough to reach the typical octane number values of gasoline products delivered at filling stations. Assuming the goal of launching a premium biodiesel or biokerosene fuel to the market, these hydroprocessed synthetic biofuels from FT biowaxes are ideal blending components.

Keywords BTL · Hydrorefining $\cdot$ Hydroprocessing · Coprocessing $\cdot$ Premium biodiesel 


$\begin{array}{ll}\begin{array}{l}\text { Notation } \\ \text { CFPP }\end{array} & \text { Cold filter plugging point, }{ }^{\circ} \mathrm{C} \\ \text { CP } & \text { Cloud point, }{ }^{\circ} \mathrm{C} \\ \text { HFRR } & \text { High-frequency reciprocating rig } \\ \text { WS1.4 } & \text { Wear scar diameter (corrected), } \mu \mathrm{m} \\ \text { FT } & \text { Fischer-Tropsch } \\ \text { WHSV } & \text { Weight hourly space velocity, } \mathrm{h}^{-1} \\ \text { DCN } & \text { Derived cetane number } \\ \text { RON/MON } & \text { Research/motor octane number } \\ \text { HPFT } & \text { Hydroprocessing Fischer-Tropsch } \\ \mathrm{m}_{\text {gas }} & \text { Mass gas fraction, kg } \\ \mathrm{m}_{\text {naphtha }} & \text { Mass naphtha fraction, kg } \\ \mathrm{m}_{\text {diesel }} & \text { Mass diesel fraction, } \mathrm{kg} \\ \mathrm{m}_{\text {Feed }} & \text { Mass feed, kg }\end{array}$

\section{Introduction}

Released greenhouse gases cause global warming with tremendous impact on climate changes around the world. Products from biological sources enable an alternative energy supply, and their use avoids increasing atmospheric carbon dioxide levels. Carbon dioxide emitted by the burning of biofuels has a short lifetime circle compared to fossil fuels, and is, therefore, climate neutral. On the other hand, fossil sources such as crude oil and coal reserves are limited. In particular, fuels produced by traditional crude oil refineries are burned in engines as well as aircraft turbines and are converted quickly to greenhouse gases. Ambitious goals of the European Union (EU) for greenhouse gas saving in the automotive sector squeeze refinery operators to increase the biocontent in fuels. Blending of fossil fuels with biofuels such as fatty acid methyl ester (FAME) is one option to fulfill EU directive requirements. Unfortunately, the blending rate of such biofuel components in standard vehicles is restricted due to missing technology adaption of vehicles. Currently, biodiesel consists of glycerin components with fatty acids that lead to corrosion and support the growth of microorganisms and plugging of filter media due to the building of a biofilm on the filter media. Bio oils such as food oils, algae oil, or jatropha oil are conditioned, treated by transesterifaction with methanol, as well as blended with fossil diesel. Another approach for producing biogenous diesel fuel is the conversion of bioproducts with existing refinery hydrotreating plants. In particular, the treatment of biogenous product blends in hydrodesulfuration (HDS) plants or mild hydrocracking plants offer a feasible opportunity. In this thermochemical process route, bioproducts such as bio oils or solid lignocellulosic biomass can be applied as feedstock for co-conversion to middle distillates.

According the renewable energy and fuel quality directives (RED, FQD), only fuels created from ligno- celluloses such as woody products can currently be defined as second-generation biofuels. These are compared to first-generation biofuels from bio oils higher credible concerning the greenhouse gas savings (GHG savings) and consist of paraffins instead of oxygenates (FAME). The accounting rates of most important biogenous diesel fuels up to 2020 are shown in Fig. 1, according FQD. Synthetic biodiesel, via Fischer-Tropsch (FT) synthesis, and diesel upgrades from FT biowaxes, via hydroprocessing, reach the currently highest account concerning GHG saving (93\%), whereas hydrotreated vegetable oil (HVO) and FAME diesel fuels are placed behind. HVO is specified by the typical hydrocarbon distribution of the fatty acid chain length distribution of vegetable oils in a range of $\mathrm{C} 14-\mathrm{C} 18$, with a high content of isoparaffins. The synthetic FT biodiesel has an extended carbon number distribution from $\mathrm{C} 8$ to $\mathrm{C} 21$, with a peak at $\mathrm{C} 12$ and a high amount of n-paraffins. FT biowax, the main product of FT synthesis, can be converted to hydroprocessed FT biodiesel (HPFT) with excellent cold flow properties and a high kerosene amount with a superior freezing point. Coprocessing of biomass via hydrotreating in existing crude oil refineries seems to be an option to create premium biofuels in the middle distillate boiling range with extraordinary properties, capable of special applications. To verify the content of hydrocarbons from biomass in fuels, biocarbon content can be measured via radiocarbon dating $\left(\mathrm{C}_{14}\right.$ method).

Olschar et al. [1] studied hydrocracking of FT waxes based on coal and a crude oil-derived n-paraffinic wax fraction to diesel with commercially available base metal catalysts at various process parameters for temperature,

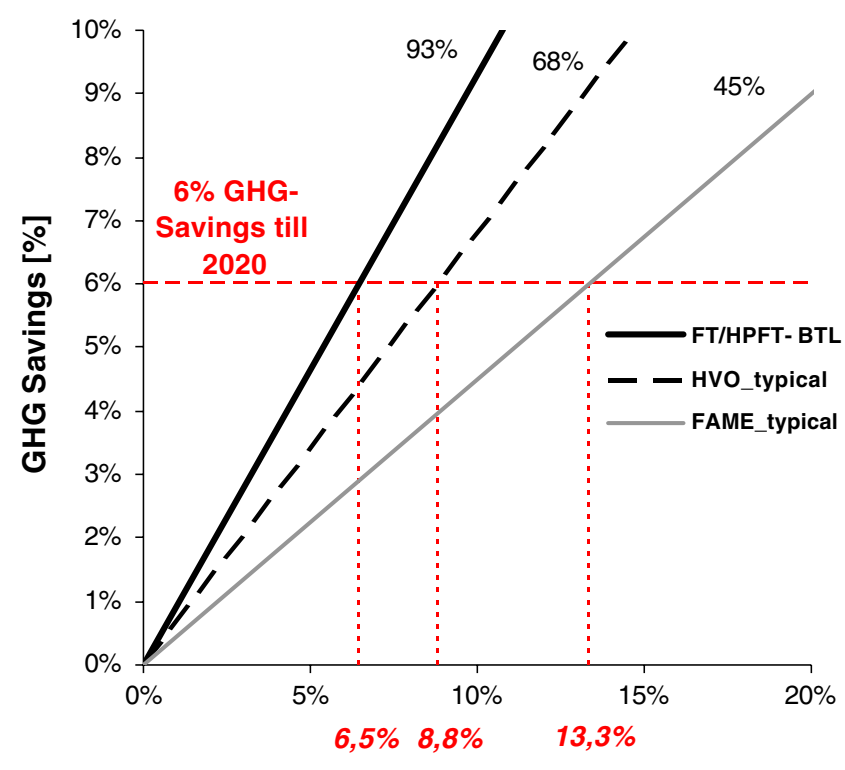

Bio- Content [Vol\%]

Fig. 1 Greenhouse gas savings (Source, FQD) 
pressure, and feed rate under mild conditions. Calemma et al. $[2,3,5]$ investigated the hydrocracking behavior of a platinum on amorphous silica-alumina catalyst and confirmed the high potential of wax hydroprocessing to highquality biofuels in the diesel boiling range. The present study describes the application of FT biowaxes as feedstock in a pilot-scale hydroprocessing unit at operating conditions very similar to an industrial-size hydrotreating plant for fossil gasoil. The experiments have been conducted with a commercially available catalyst at mild conditions. Various test runs were carried out under a variation of the reactor temperature and feed rate, based on catalyst mass defined as weight hourly space velocity (WHSV). The purpose was to produce fuels in the diesel, kerosene, and gasoline boiling ranges as well as light hydrocarbons and to determine the effect on catalyst behavior and product distribution. The results of this study shall support the realization of the production of cohydroprocessing in the refinery with the purpose of reducing fossil $\mathrm{CO}_{2}$ emissions.

Yates et al. [7] investigated diesel fuels with a high knock resistance and postulated an equation for the calculation of the derived cetane number (DCN) from the ignition delay time measured by the ignition quality tester (IQT).

\section{Catalytic cracking/isomerization}

The conversion of FT biowaxes to biofuels is achieved by a catalytic cracking process (Fig. 2) under the presence of hydrogen via bifunctional catalysts (acid and hydrogenation function). The catalytic cracking of hydrocarbons can be achieved, involving carbocations as intermediates - carbonium ions for monomolecular cracking and carbenium ions for bimolecular cracking (cleavage of $\mathrm{C}-\mathrm{C}$ bond in the $\mathrm{B}$ position to positively-charged carbon) with hydride transfer. The monomolecular pathway is important at the entrance of the reactor, whereas the bimolecular mechanism dominates all other stages. Carbenium ions are generated by hydride abstraction from alkanes. Lewis acid sites (having the ability to accept an electron pair) of aluminosilicate catalyst matrix abstract hydride, which leads to the dehydrogenation of alkane and the formation of an olefin. The olefin is protonated at the adjacent Brønsted acid site (having the ability to donate a proton) of the catalyst matrix to create carbenium ions. Generated primary carbenium ions undergo a rapid hydride shift to form more stable secondary and tertiary ions. Secondary ions are cracked at the $\mathrm{C}-\mathrm{C}$ bond in the $\beta$ position to generate smaller $\alpha$-olefins and primary carbenium ions. Smaller carbenium ions are stabilized by hydrogen abstraction from longer branched hydrocarbons or excess hydrogen-saturating olefins. The splitting process iterates as long as terminated by the formation of the $\alpha$-olefin propene. The isomerization dewaxing of heavy gas oils under mild conditions over zeolite catalysts is postulated via the catalytic network, as pointed out in Fig. 5.

Chevron Inc. has developed the isodewaxing process, based on bifunctional catalysts, to combine isodewaxing with hydrogen pretreating and hydrofinishing. Catalysts are based on Ni-W/Zeolite on amorphous aluminosilicate, providing higher middle distillate selectivity, superior quality of the middle distillate with zeolites HZSM-5, ZSM-22, ZSM-23, and SAPO11.

\section{Experimental}

\subsection{Experimental setup}

The experimental test program was conducted in a pilotscale hydroprocessing unit (Fig. 3) of OMV Refining \& Marketing. The two catalyst beds (catalysts A and B) in a fixed-bed reactor tube are separated by a spacer material. Both catalysts, as well as the inert spacer material, are porous to enable the diffusion of liquefied waxy feed. Furthermore, the fixed-bed reactor is streamed with hydrogen and operates under pressure in order to saturate hydrocarbon fragments and to reduce the formation of coke on the catalyst particle surface. The first catalyst bed is diluted by silica carbide and acts as a pretreater for hydrogenation of impurities (compounds with heteroatoms) in waxy feed. This treatment ensures protection of the second catalyst that is responsible for mild cracking
Fig. 2 Reaction network for catalytic cracking

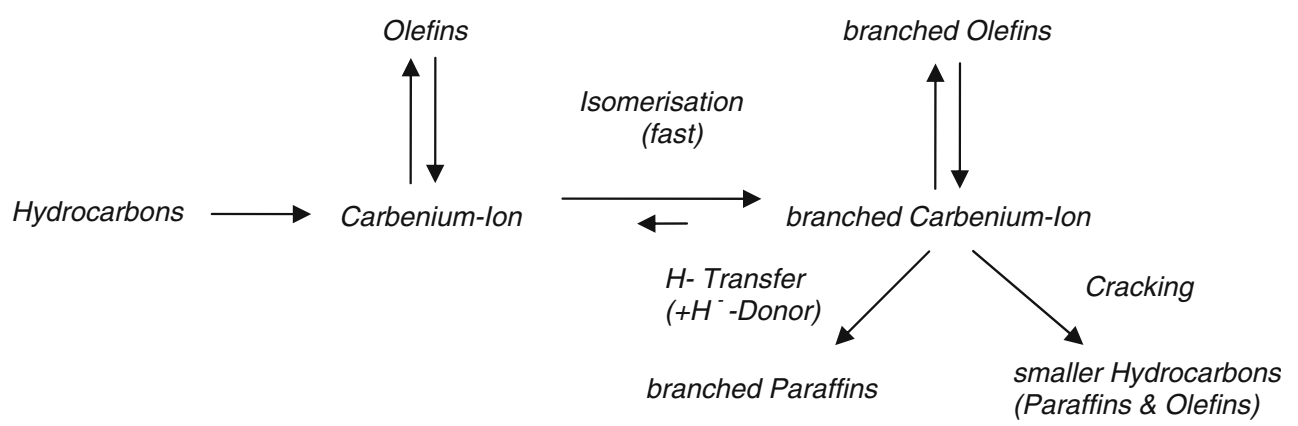




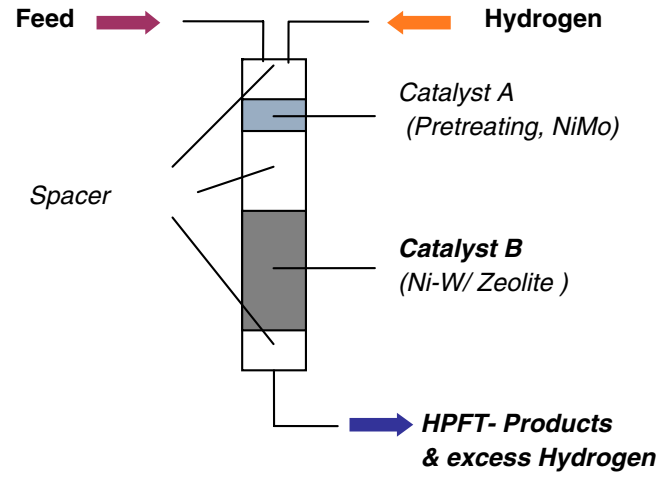

Fig. 3 Schematic of pilot plant (OMV)

and isomerization of long hydrocarbon molecules into smaller and branched fragments. The schematic of the fixed-bed reactor for hydroprocessing of FT biowaxes is shown in Fig. 3.

Additionally, the operating points in the reactor chamber are defined by the process parameters, the reactor temperature, and the WHSV under constant pressure conditions, as shown in Fig. 4. The number of each process point indicates the sequence of investigation.

\subsection{Applied feedstock}

The applied standard feedstock for hydrotreating plants in refineries such as HDS/hydrodenitrification and dewaxing via hydrocracking or isomerisation is delivered as middle distillates from atmospheric distillation (gasoils) as well as the top-side bulk from vacuum distillation (vacuum gasoil). To investigate the capability of hydroprocessing with biogenous products, pure FT biowaxes from the CHP-biomass plant in Guessing have been applied with a composition as shown in Fig. 5. FT

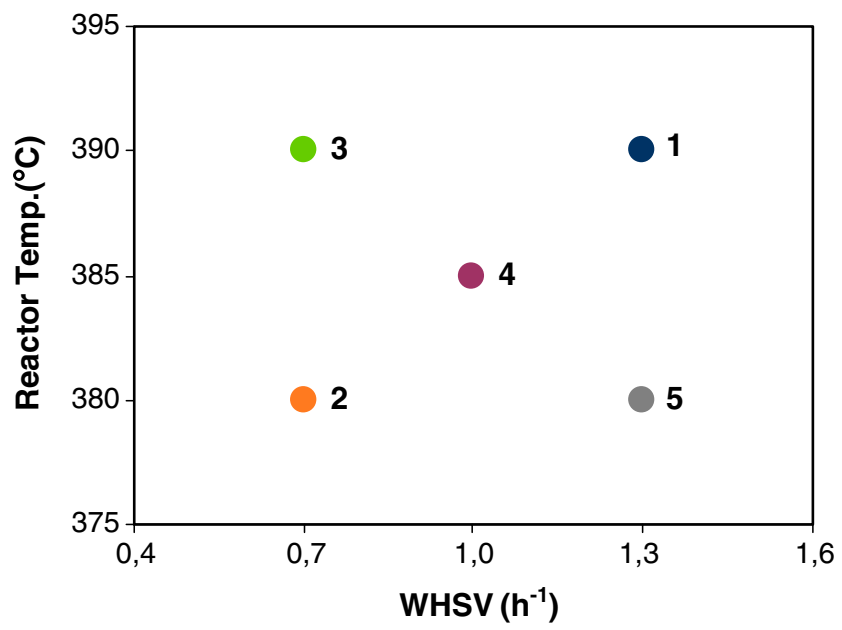

Fig. 4 Test program (operating points) biowax is the main product of FT synthesis originated from product gas that is generated by gasification of woody biomass. Besides the main component, $\mathrm{n}$-paraffins, biowaxes consist of appreciable amounts of unsaturated hydrocarbons (olefins) as well as isoparaffins and oxygenates (alcohols). The carbon number spectrum shows a hydrocarbon chain length profile that can be expressed by an Anderson-Schulz-Flory distribution curve with the chain growth probability factor $\alpha \sim 0.9$. The properties of the FT biowax from Guessing with a high amount of hard wax ( $>\mathrm{C} 40$; boiling point, $\left.T_{\mathrm{b}}>300^{\circ} \mathrm{C}\right)$ of $62 \%$ are presented in Table 1. A complete liquefaction of pure FT biowax for pumping into the reaction chamber can be guaranteed at $130^{\circ} \mathrm{C}$.

\subsection{Execution of the experiments}

The hydroprocessing experiments were conducted at different operating points defined by a couple of process parameters reactor temperature and WHSV at constant pressure $(5.8 \mathrm{MPa})$ in a fixed-bed reactor. A pretreating catalyst $\mathrm{A}$ and a processing catalyst $\mathrm{B}$, operating in the hydrotreating plant (OMV), have been filled in the reaction chamber with an inert material (spacer) in between to avoid discharge. This separated configuration of catalyst beds corresponds with an industrial-size hydrotreating plant. The fixed-bed reactor of the pilot plant is heated with electric coils and streamed with hydrogen. Liquefied biowax is filled continuously into the reaction chamber $(20-60 \mathrm{~g} / \mathrm{h})$ and contacts the hot catalyst particles. The heterogeneous catalysis proceeds within the reaction chamber in the liquid phase by cracking and isomerization of large molecules. A typical product spectrum at operation in the fixed-bed reactor, as illustrated in the next chapter, will be achieved. All experiments are conducted as continuous test runs, where operation temperatures and pressures in the reactor

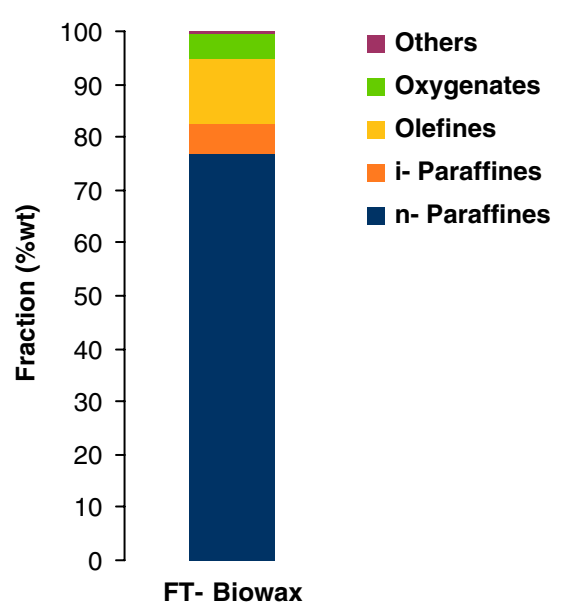

Fig. 5 Composition of FT biowax (Guessing) 
Table 1 Properties of FT Biowax (Guessing)

\begin{tabular}{ll}
\hline Carbon range & $\mathrm{C} 25-\mathrm{C} 105$ \\
\hline Melting range & $38-110^{\circ} \mathrm{C}$ \\
Amount $\left(T_{\mathrm{b}}>300^{\circ} \mathrm{C}\right)$ & $62 \% \mathrm{wt}$. \\
$\rho_{130^{\circ} \mathrm{C}}$ & $0.742 \mathrm{~kg} / \mathrm{dm}^{3}$ \\
$\gamma_{130^{\circ} \mathrm{C}}$ & $6.62 \mathrm{~mm}^{2} / \mathrm{s}$ \\
$\mathrm{C} / \mathrm{H} / \mathrm{O}$ & $85 / 14.7 / 0.3 \% \mathrm{wt}$. \\
\hline
\end{tabular}

chamber of the pilot plant have been monitored online. The gaseous fraction releases the product vessel, expands via pressure reducing valve, and is analyzed by gas chromatography (GC). The desired products obtained are separated by distillation according to the defined boiling ranges and analyzed via gas chromatography. Additionally, the chemical structure of liquid products from FT synthesis and hydroprocessing is encoded by $2 \mathrm{dGC}$ $(\mathrm{GC} \times \mathrm{GC})$ to achieve detailed information about the composition of biofuels.

\subsection{Product composition}

The product groups (lumps), obtained by catalytic conversion under the presence of hydrogen, are listed below, whereas the conversion is defined as the sum of the gas, naphtha, and the diesel yield. Furthermore, the liquid crude is separated into naphtha, diesel, and a residue, according to defined boiling ranges presented in Fig. 6. The gas fraction contains $\mathrm{C} 1$ to $\mathrm{C} 4$ hydrocarbons, mainly saturated paraffins such as $\mathrm{i} / \mathrm{n}$-alkanes, and is contaminated with excess hydrogen from feeding the reactor. The diesel fraction contains a high amount of kerosene, ranging between $180^{\circ} \mathrm{C}$ to $225^{\circ} \mathrm{C}$. The yield of the byproduct water is negligible because the oxygen content of FT biowaxes is only $0.3 \%$ by mass, and coke is generated on the catalyst particle surface. For evaluation of fuel properties, the boiling range of HPFT-diesel fraction is equal to FT diesel and specified from 180 $320^{\circ} \mathrm{C}$.

\section{Results and discussion}

Based on the results obtained, real tendency of conversion, depending on process parameters (temperature and WHSV), can be recalculated, considering the deactivation of the catalyst. Unsaturated components such as olefins and impurities (compounds with heteroatoms) in the waxy feed can be mentioned as a reason. Olefins supply the formation of a coke layer around catalyst particles, whereas water, produced by the hydrogenation of oxygen content in FT biowaxes, diffuses in the catalyst pore structure. Higher feed mass flow, based on catalyst mass defined as WHSV, reduces conversion, whereas diesel yield increases slightly. At a higher reactor temperature, the conversion gradient, depending on the WHSV rate, shows a larger increase. In Fig. 7, tendencies can be approximated by a regression curve in the investigated parameter field.

The different lump yields obtained during the test runs are pointed out in Fig. 8. The complete diesel yield is divided into a kerosene yield $\left(180-225^{\circ} \mathrm{C}\right)$ and the remaining diesel, with the higher diesel boiling range between $225^{\circ} \mathrm{C}$ to $320^{\circ} \mathrm{C}$. Test runs 1 to 3 show only a slight difference of diesel yield $\left(180-320^{\circ} \mathrm{C}\right)$, whereas the highest naphtha amounts can be detected at run $3\left(390^{\circ} \mathrm{C}\right.$; WHSV $\left.=0.67 \mathrm{~h}^{-1}\right)$. Therefore, conversion-the sum of yields below $320^{\circ} \mathrm{C}$-reaches a value of up to $80 \%$ wt., as shown in Fig. 7. Runs 4 and 5 indicate a high-residue yield as the consequence of continuous coking (formatted coke yield), resulting in partial deactivation of the catalyst surface. Deactivation of the catalyst leads to reduction of cracking efficiency coupled with the decline of isomerization and branching degrees. Furthermore, a negative

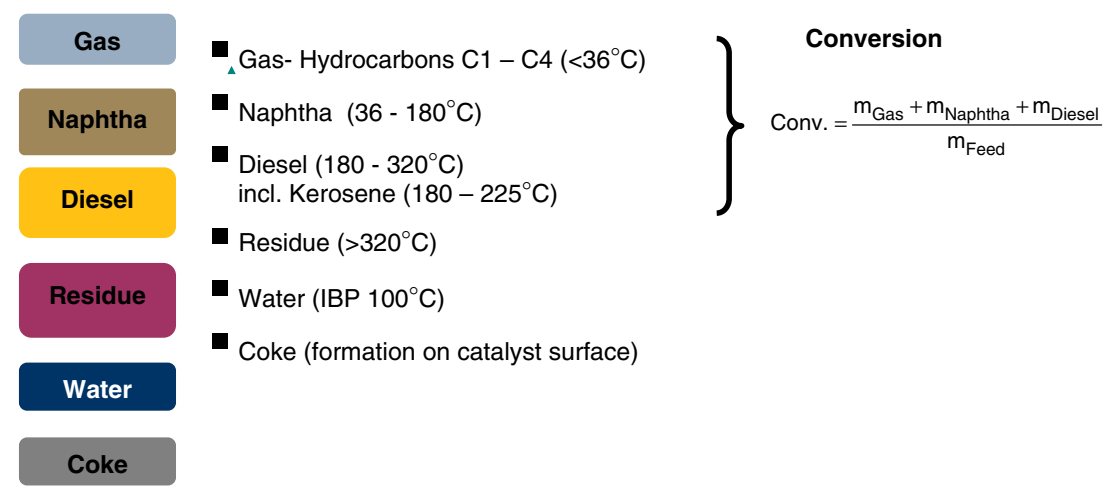

Fig. 6 HPFT products and conversion 
Fig. 7 Conversion depending on process parameters

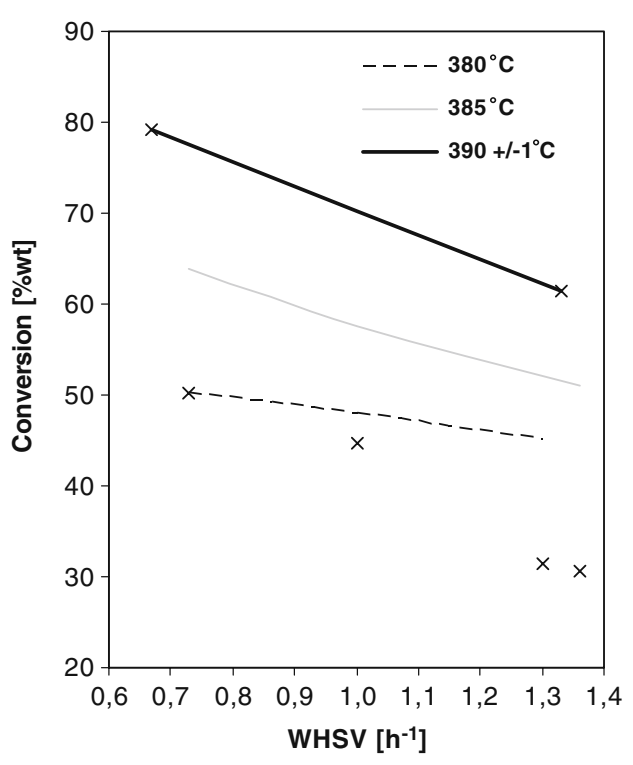

impact on fuel amounts and product quality concerning cold flow properties can be observed. The detailed product composition analysis method offers a high resolution for the detection of molecules via two-dimensional gas chromatography $(\mathrm{GC} \times \mathrm{GC})$, separating apolar hydrocarbons and polar oxygenates such as alcohols and ketones. The carbon number distribution calculated from results of $\mathrm{GC} \times \mathrm{GC}$ analysis illustrates the chemical structure of biofuels. In Fig. 9, the FT-diesel profile from synthesis is encoded via separated structure groups pointed out as carbon number distribution with a range from C8 to C20. The overall curve is similar to a Gaussian distribution with a peak at $\mathrm{C} 13$. The composition consists of $70 \% \mathrm{wt} n-$ paraffins responsible for excellent cetane number $(\mathrm{CN})$, high amounts of unsaturated olefins $(20 \% \mathrm{wt})$ and oxygenates. Low amounts of isoparaffins and aromatics can be detected. HPFT diesel from hydroprocessing of FT biowaxes at $380^{\circ} \mathrm{C}$ and WHSV $=0.7 \mathrm{~h}^{-1}$ differs from FT diesel by a dominant isoparaffin content $(<90 \% \mathrm{wt})$ as well as low n-paraffins and negligible amounts of aromatics (Fig. 10). Amounts of alkenes and oxygenates lie under the detection limit. The spectrum of HPFT diesel has a narrower distribution compared to FT diesel, ranging from C10 to $\mathrm{C} 19$ at the same boiling range as FT diesel. In addition, the distribution is concentrated in the kerosene boiling range, with a plateau at $\mathrm{C} 11$ to $\mathrm{C} 15$ and a barely observable peak at $\mathrm{C} 14$. The high amount of isoparaffins improves cold flow properties (CP, CFPP) significantly, reaching excellent values as low as $-60^{\circ} \mathrm{C}$. Finally, the results of $\mathrm{GC} \times \mathrm{GC}$ analysis from HPFT naphtha, obtained at hydroprocessing conditions of $380^{\circ} \mathrm{C}$ and $\mathrm{WHSV}=0.7$, are illustrated in Fig. 11. The naphtha fraction ranges from
Fig. 8 Product yields

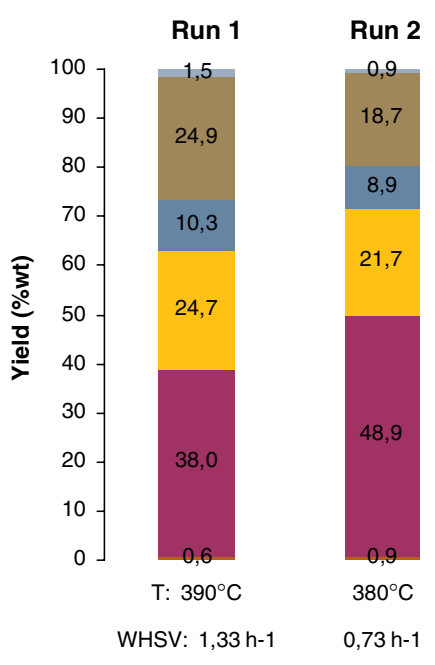

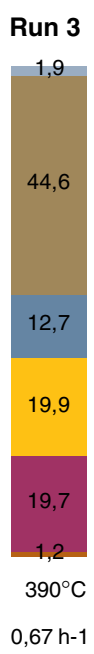
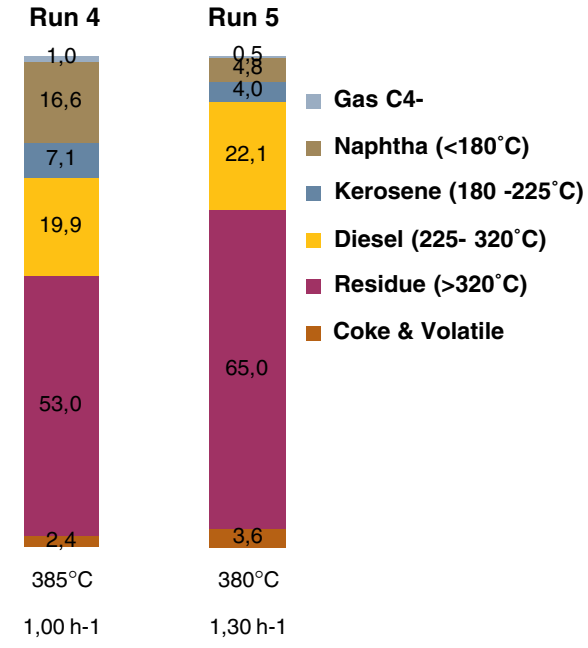

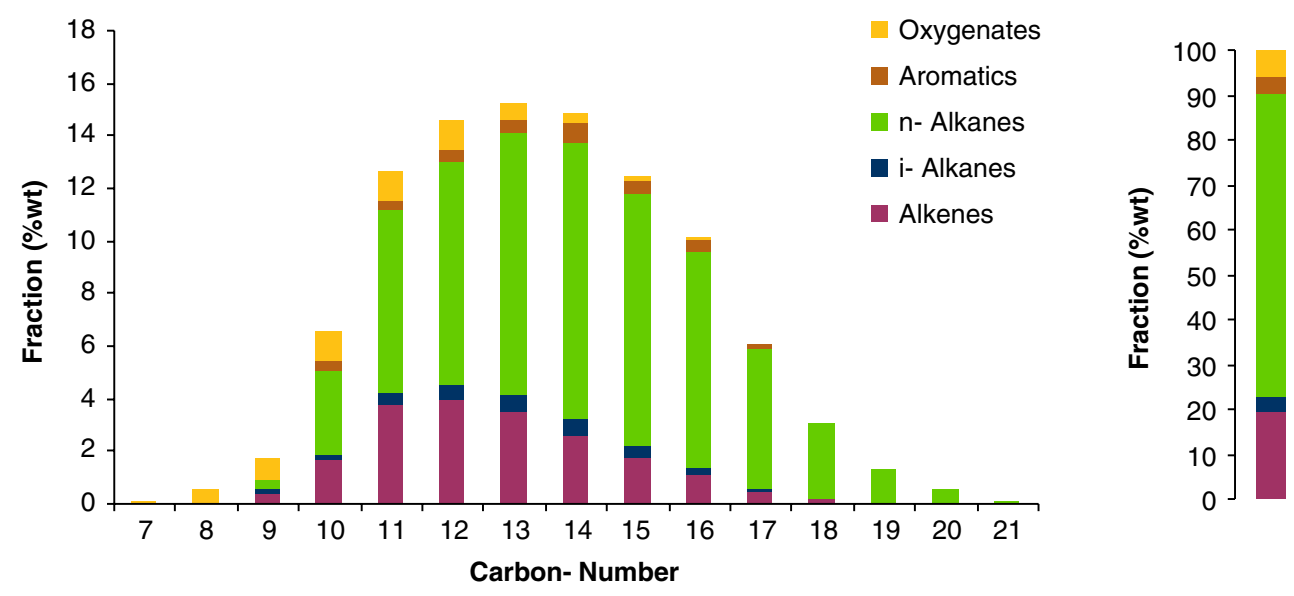

Fig. 9 Profile and composition of FT diesel from Guessing $(\mathrm{GC} \times \mathrm{GC})$

C4 to C12 and contains high amounts of isoparaffins, nparaffins, and even unsaturated hydrocarbons (olefins) as well as negligible amounts of cyclic alkanes and aromatics. The physicochemical properties of FT and HPFT components are collected in Table 2. High amounts of isoparaffins from HPFT-diesel lead compared to FT diesel to superior quality concerning cold flow properties at hardly lower derived cetane number (DCN), according the SAE paper 2007-01-0026. Furthermore, cloud point and cold filter plugging point reach values as low as $-60^{\circ} \mathrm{C}$. The corrected wear scar diameter WS1.4 of HPFT dieseldetermined via high-frequency reciprocating rig-is out of specified upper limit $(\leq 460 \mu \mathrm{m})$, according standard EN590 requiring a lubricity additive to conform with standards. Although the isoparaffin content of HPFT naphtha is high, only low octane numbers (RON/MON) of $<40$ could be measured. The branching degree of isoparaffins from the HPFT-naphtha fraction is obviously not high enough to reach typical octane number values of gasoline products delivered at filling stations.

\section{Conclusion}

High-boiling FT biowaxes from lignocellulosic biomass were hydroprocessed to second-generation biofuels in a pilot plant at OMV with commercially available catalysts. The first Ni/Mo-based catalyst of the fixed-bed reactor acts as a pretreater responsible for hydrogenation of impurities (e.g., heteroatoms) in waxy feed to protect the second catalyst. The latter performs dewaxing of waxy feedstock via mild hydrocracking and isomerization. Reactor temperature and WHSV have been varied to investigate the effect of the process parameter on product composition and the characteristic of obtained fuel fractions. All continuous test runs were performed without essential modifications to the pilot plant and at operating conditions of an industrial-size hydrotreating plant, focusing on a future coprocessing with fossil gasoil. Hydroconversion of liquefied waxy feed generates the products-gases, naphtha, diesel including kerosene, and a waxy residue. The conversion-sum of hydrocarbon
Fig. 10 Profile and composition of HPFT diesel $(\mathrm{GC} \times \mathrm{GC})$

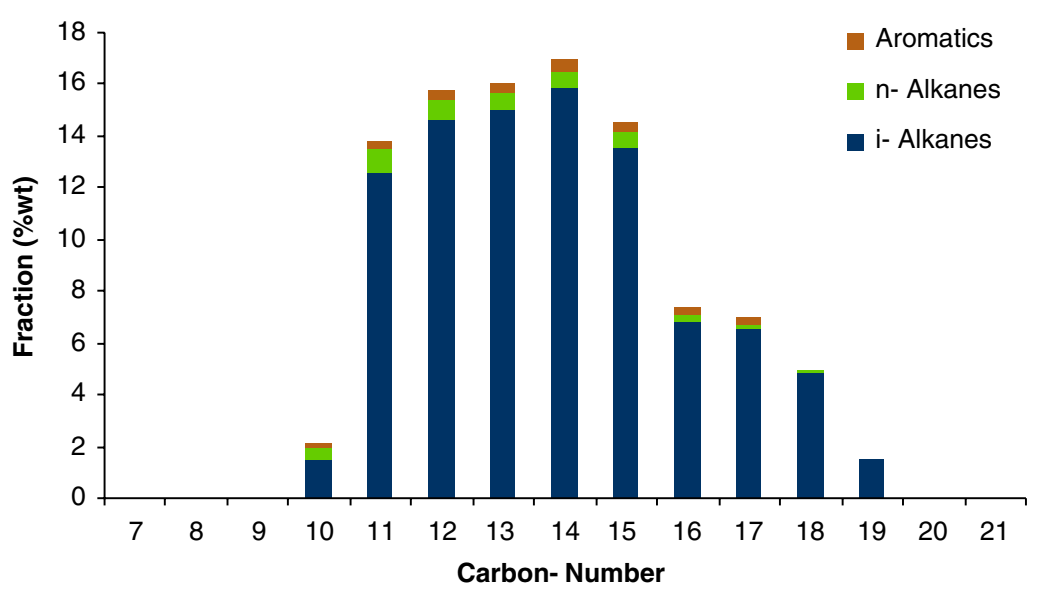



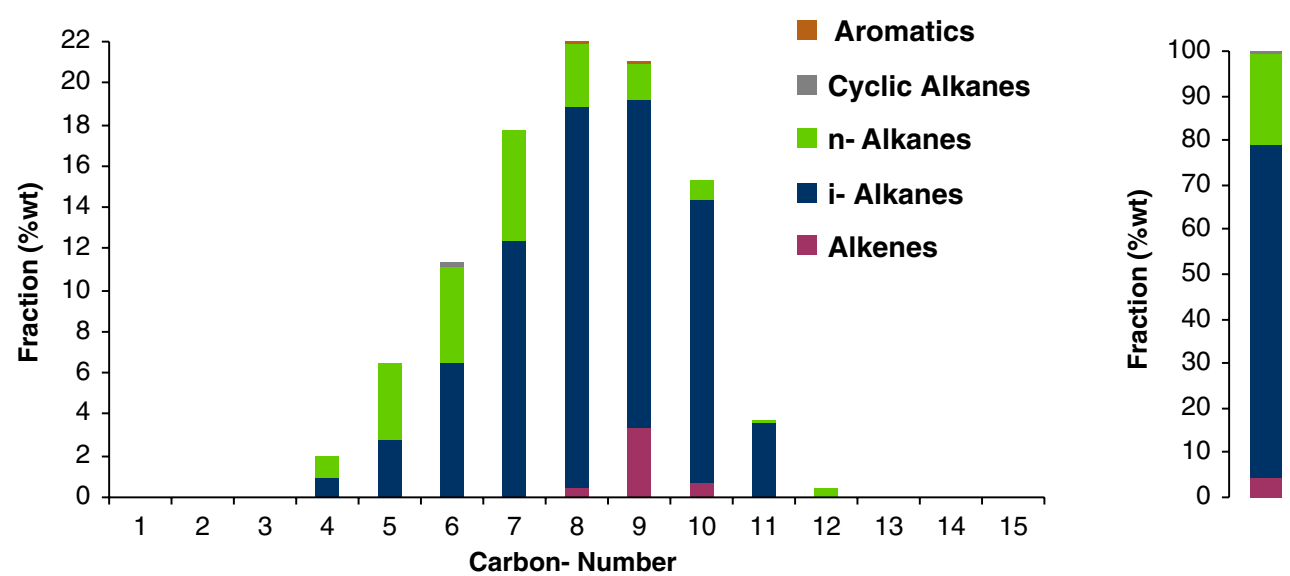

Fig. 11 Profile and composition of HPFT naphtha $(\mathrm{GC} \times \mathrm{GC})$

gases, naphtha, and diesel fraction, based on the waxy feed-diversify by shifting process parameters. A high reaction temperature as well as a low WHSV rate increase conversion and supply the generation of a high naphtha fraction at a constant diesel amount and vice versa. HPFT diesel, produced by a dewaxing catalyst and operated at mild conditions, differs from FT diesel by a marginal lower derived cetane number (DCN 79.6), according SAE paper 2007-01-0026, but, remarkably, better cold flow properties. The cloud point $(\mathrm{CP})$ as well as the cold filter plugging point (CFPP) of HPFT diesel reaches values as low as $-60^{\circ} \mathrm{C}$ as the result of a high kerosene amount and a considerable content of isoparaffins. Furthermore, the bio kerosene fraction (C10 $\mathrm{C} 14)$ reaches an extremely low freezing point, as low as $-80^{\circ}$ $\mathrm{C}$ and is capable as a blending component for jet fuels. On the other side, HPFT naphtha has only low octane numbers (RON/ MON) comparable with straight-run naphtha from a refinery, but is an ideal feedstock for steam cracking to produce olefins for the petrochemical industry. Nevertheless,
FT biowax contains a high amount of unsaturated hydrocarbons (alkenes), which causes the formation of a coke layer around the catalyst particle surface, resulting in partial deactivation of the catalyst. Sensibility of the catalyst towards steam originating from hydrogenation of oxygenates from FT biowaxes influence catalyst activity and, therefore, reaction behavior over runtime. Further investigations concerning the aging tendency of catalyst in operation with FT-biowax blends are essential to guarantee unproblematic coprocessing in existing hydrotreating plants of refinery. The high accounting rate of second-generation biofuels, according the FQD and RED, supports refinery operators to fulfill fossil $\mathrm{CO}_{2}$ saving requirements via hydro (co)processing of lignocellulosic biomass-derived products.

Acknowledgments This project, funded by FFG association, is carried out in cooperation with the Vienna University of Technology, with the support of Mr. Rauch, Prof. Hofbauer, Prof. Geringer, the biomass CHP-plant operator, and Mr. Aichernig from Reprotec Inc.
Table 2 Physicochemical properties of synthetic fuels

\begin{tabular}{lllll}
\hline Parameter & Unit & FT diesel & HPFT diesel & HPFT naphtha \\
\hline Boiling range & ${ }^{\circ} \mathrm{C}$ & $180-320$ & $180-320$ & $36-180$ \\
C-number range & - & $\mathrm{C} 8-\mathrm{C} 20$ & $\mathrm{C} 10-\mathrm{C} 19$ & $\mathrm{C} 4-\mathrm{C} 12$ \\
i/n-Paraffins & $\%$ & $3.3 / 67.4$ & $87.5 / 9.9$ & $74.2 / 20.9$ \\
Alkenes/aromatics & $\%$ & $19.6 / 3.5$ & $-/ 2.6$ & $4.6 / 0.3$ \\
Oxygenates & $\%$ & 6.2 & - & - \\
DCN & - & 83 & 79.6 & - \\
Flash point & ${ }^{\circ} \mathrm{C}$ & 77.7 & 80 & - \\
$\mathrm{CP} / \mathrm{CFPP}$ & ${ }^{\circ} \mathrm{C}$ & $-9 /-13$ & $-56 /-58$ & - \\
$\rho_{15^{\circ} \mathrm{C}}$ & $\mathrm{kg} / 1^{3}$ & 0.769 & 0.774 & - \\
$v_{40^{\circ} \mathrm{C}}$ & $\mathrm{mm} / \mathrm{s}$ & 1.88 & 2.03 & - \\
WS1.4 (HFRR) & $\mu \mathrm{m}$ & 435 & 622 & $39 / 35$ \\
RON/MON & - & - & - & \\
\hline
\end{tabular}




\section{References}

1. Olschar M, Endisch M, Dimmig TH, Kuchling TH (2007) Investigation of catalytic hydrocracking of Fischer Tropsch wax for the production of transportation fuels. OIL GAS European Magazine 33:187

2. Calemma V (2010) Middle distillates from hydrocracking of FT waxes composition, characteristics and emission properties. Catal Today 149:40-46

3. Calemma V (2005) Hydroconversion of Fischer-Tropsch waxes. Catal Today 106:282-287
4. Mapior M (2010) Effects of the operating variables on hydrotreating on heavy gas oil: experimental, modeling and kinetic studies. Fuel 89:2536-2543

5. Calemma V, Peratello S, Perego C (2000) Hydroisomerization and hydrocracking of long chain n-alkanes on Pt/amorphous $\mathrm{SiO} 2$ A12O3 catalyst. General, Applied Catalysts A, pp 207-218

6. Leckel D (2006) Diesel selective hydrocracking of iron- based Fischer Tropsch waxes, fraction C15-C45, using a MoO3-modified noble metal catalyst. Energy Fuels $\mathrm{Nr}$ 6:2330-2336

7. Yates ADB, Viljoen C, Metcalf O (2007) An accurate determination of the cetane number value of GTL diesel. SAE Paper 01-0026 